\title{
Barriers for physical activity in older adults users of fitness zones
}

\author{
Barreiras na prática de atividade física de idosos usuários de academias \\ da terceira idade
}

\section{AUTHOR'S \\ Daniel Vicentini de Oliveira ${ }^{1}$ (D) \\ Caio Rosas Moreira ${ }^{2}$ (D) \\ José Roberto A. do Nascimento Junior ${ }^{3}$ (iD \\ Gabriel Lopes Dias Rodrigues ${ }^{4}$ (D) \\ Diogo Alves da Silva ${ }^{4}$ (D) \\ Cláudia Regina Cavaglieri ${ }^{1}$ (i) \\ 1 Campinas State University, Departament o
Gerontology, Campinas, São Paulo, Brazil. \\ 2 Maringá State University, Departament of \\ Physical Education, Maringá, Paraná, Brazil. \\ 3 Federal University of the Vale do São Francisco, College of Physical Education, Petrolina, Pernambuco, Brazil. \\ 4 Metropolitan College of Maringá, Departament of Physical Education, Maringá, Paraná, Brazil.}

\section{CORRESPONDING}

Daniel Vicentini de Oliveira

d.vicentini@hotmail.com

Avenida Londrina, 934, Apartamento 1907, torre A. Maringá, Paraná, Brasil.

CEP: 87050-730.

DOI

$10.12820 /$ rbafs. $23 \mathrm{e} 0025$

\begin{abstract}
This study aimed to investigate perceived barriers for physical activity in older adults while in fitness zones (FZ). Participants were 970 older adults, users of 34 out of 57 FZ in the city of Maringá, Paraná, who responded to a sociodemographic questionnaire, the mini-mental state examination and the Questionnaire on barriers for physical activity. The results indicated high indexes of perception of barriers for physical activity in FZ. Older adults with a regular/bad perception of health had fewer barriers, while males, up to 70 years old and who received more than three minimum wage pay perceived more barriers $(\mathrm{p}<0.05)$ when compared to other groups, indicating the physical limitations and the fear of getting injured as the most frequent differences. We can conclude that FZ are locations that present a high number of barriers of older adults to be physically active. Moreover, older adults with a certain profile seem to perceive more barriers for the use of $\mathrm{FZ}$, with the most common justification being physical limitations and the fear of getting injured while being physically active.
\end{abstract}

Keywords: Physical activity; Elderly; Health of the elderly; Health services for elderly; Cross-sectional studies.

\section{RESUMO}

Este estudo teve como objetivo investigar as barreiras percebidas por idosos para a prática de atividade física nas Academia da Terceira Idade (ATI). Participaram da pesquisa 970 idosos usuários de 34 das 57 ATI no município de Maringá, Paraná, os quais responderam um questionário sociodemográfico, o Mini Exame do Estado Mental e o Questionário de Barreiras para a prática da Atividade Física. Os resultados indicaram altos indices de percepção de barreiras para a prática de atividade física nas ATI. Idosos com percepção de saúde regular/ruim apresentam menor indice de barreiras, enquanto homens, idosos até 70 anos e que recebem mais de três salários minimos percebem maiores barreiras $(p<0,05)$ quando comparado com outros grupos, indicando as limitaçôes físicas e o medo de se lesionar como as diferenças mais frequentes. Conclui-se que as ATI é um local que apresenta grandes barreiras para os idosos praticarem atividade física. Ainda, idosos que apresentam um determinado perfil tendem a reconhecer maiores barreiras para a utilização das ATI, tendo como justificativa principalmente as limitações físicas e o medo de se lesionar durante as atividades.

Palavras-chave: Atividade física; Idoso; Saúde do idoso; Serviços de saúde para idosos; Estudos transversais.

\section{Introduction}

Over the next 30 years, the older adult population in Brazil will triple, becoming approximately $30 \%$ of the total population ${ }^{1}$ and being larger than the population of children up to 14 years old in 2030. This is due to the lower birth and death rates of the Brazilian population ${ }^{2}$. Therefore, there is an increase in the concern on what is the mental health status of the older population. Social and political programs to promote healthy lifestyles for Brazilians have been implemented ${ }^{3,4}$, with a main focus on older adults ${ }^{5}$. However, it is necessary to investigate what are the main barriers that the older adults perceive in the search of a healthy lifestyle in order to better cater future interventions to this population. 
Physical activity is one of the main tools to maintaining a healthy lifestyle at any age range. Therefore, it is important to identify not only reasons that facilitate but also those that prevent older adults of being physically active in different contexts for a better development of the Brazilian population. Barriers for physical activity are present in all ages ${ }^{6,7}$, but older adults have had a greater focus in social programs ${ }^{5}$.

One of the main interventions for this population were the Fitness Zones (FZ). Destined to be used for physical exercise that improve flexibility, strength, cardiovascular health, and mobility, the FZ tend to promote an environment where one could have a healthy lifestyle ${ }^{8}$. Nonetheless, even though this is equipment where users could comply with recommended levels of moderate to vigorous physical activity, not knowing how to use equipment and the lack of orientation at $\mathrm{FZ}^{9}$ are still factors that could prevent physical activity in those locations.

Therefore, it is necessary to identify the barriers for physical activity in FZ, once studies on barriers for older adults typically included sedentary ${ }^{3}$ or both sedentary and active participants ${ }^{10-12}$, but no studies have investigated the use of FZ. This leads to a gap in the literature involving barriers for use of $\mathrm{FZ}$ in the promotion of physically active older adults, once these locations have been built in several cities around the country and the world. This study aims at investigating the perceived barriers in older adult users of $\mathrm{FZ}$ in the city of Maringá, Paraná, verifying differences according to gender, age group, and perception of health.

\section{Methods}

This is an epidemiological, quantitative, and cross-sectional study. Participants were 970 older adults, chosen intentionally and by convenience, users of fitness zones in the city of Maringá, state of Paraná. Due to the low prevalence of older adult users in some FZ (as reported by the Municipal sport and leisure secretariat), and/ or precariousness in the environment and structures, $23 \mathrm{FZ}$ were excluded from data collection. Therefore, from a total of $57 \mathrm{FZ}$ in the city at the time of data collection, 34 were studied. Inclusion criteria were older adults from both genders, users of at least one of the FZ in the study, with preserved hearing and speech that would allow responding to the questionnaires. Older adults who needed accessories for walking, with neurological deficits and informed by caretakers and/ or family members at the time of data collection, unca- pable of engaging in the study, were not included. Also those with cognitive deficits when assessed by the mini-mental state examination (MMSE). This study was approved by the Institutional Review Board of the Metropolitan University of Maringá under protocol number 2.255.102/2017 (CAAE: 72185817.1.0000.8036).

The Sport and Leisure Secretariat was contacted prior to the beginning of the study for authorization to collect data in FZ. After this, the same department verified the number of $\mathrm{FZ}$ and their locations throughout the city (except those in districts). Those were then divided into north, south, east and west regions and a random selection determined those included in the study.

A team of 10 researchers was previously trained and, after a pilot study for data collection, they were distributed among the locations. Researchers were to approach the older adults in FZ, in different days of the week and periods of the day. Those who accepted to participate signed the Informed Consent Form. Instruments were then administered as individual interviews to avoid any misunderstanding or difficulty in reading by the participants, and interviews lasted approximately 20 minutes. Data collection occurred June through August 2017.

The MMSE is composed by questions grouped into seven categories: temporal orientation, registration, attention and calculation, recall, language and praxis $^{13}$. Cut points used for exclusion by the MMSE are: 17 for illiterate; 22 for older adults with education between 1 and 4 years; 24 for those with education between 5 and 8 years; and 26 for those with 9 or more years of education.

These cut points were based on the Brucki et al. ${ }^{14}$ criteria, corresponding to the mean obtained by these authors for each education level, minus one standard deviation. Older adults classified below the cut point specific to their education were excluded.

To characterize socio demographics and health of older adults, a semi-structured questionnaire was used, composed by information related to gender (male; female), marital status (married or living with partner; single; divorced; widowed), age group (60 - 60 years old; 70 - 79 years old; 80 years old or more), monthly income in minimum wage (MW) as referenced by the 2017 Demographic Census by the Brazilian Institute of Geography and Statistics (IBGE) (1 - 2 MW; 2.1 - $3 \mathrm{MW}$; > $3 \mathrm{MW}$ ), education (did not go to school; incomplete elementary school; complete elementary school; complete high school; complete college), home 
ownership (yes; no), skin tone (White; black; other), retirement (yes; no), self-perception of health status (excellent; very good/good; bad/regular), comparison of own health with someone of same age (better; same; worse), use of medication (none; $1-2$; more than 2) and recommendations to use FZ (medical prescription; prescription by other health professional; family/ friends; not recommended by anyone).

At last, the questionnaire with barriers for physical activity was administered as proposed by Martins and Petroski ${ }^{15}$, which allows the identification of obstacles to engage in behaviors that could help prevent disease and improve health. This instrument presents a table with 20 questions, with daily life themes such as work hours, study hours, family commitments, lack of adequate weather, lack of available space for physical activities, lack of equipment, daily household chores, lack of company, lack of social support, lack of financial resources, moodiness, fear of injuries, physical limitations, mild pain or discomfort, lack of energy, lack of physical abilities, lack of knowledge or orientation on physical activity, unsafe environment (crime), concern with physical appearance and lack of interest. For each question a level of perception of such barrier for physical activity is computed between "never" (1) and "always" (5). Cronbach's alpha for this instrument was 0.87 , indicating high reliability.

To verify the importance of each of the barriers studied, the corresponding value for percentage of cases for each barrier was cited as "always" or "almost always", as a perceived barrier; "sometimes", "rarely", and "never" were not considered as preventative for physical activity and were identified as "non-perceived barriers".

Data analyses were conducted using SPSS version 22.0 through descriptive and inferential statistics. Frequency and percentage were used as descritptive measures for categorical variables. The comparison of proportions were obtained through Chi-squared test for nominal variables and Chi-squared for tendency for ordinal variables. A significance level of $5 \%$ was used for both tests.

\section{Results}

A total of 970 older adults participated in the study, from both gender (428 males and 542 females) aged between 60 and 91 years $(68.93 \pm 6.95$ years). It is noticeable (Table 1) most older adults were married (62.1\%), aged between 60 and 69 years (60.4\%), white (75.9\%), retired (72.9\%) and with a monthly income of
1-2 MW (53.3\%). It was also observed that most older adults did not complete high school (63.9\%).

Table 1 - Sociodemographic profile of older adults users of FZ in the city of Maringá, Paraná, Brazil, 2017 (n = 960).

\begin{tabular}{|c|c|c|}
\hline Variables & $\mathrm{n}$ & $\%$ \\
\hline \multicolumn{3}{|l|}{ Gender } \\
\hline Male & 428 & 44.2 \\
\hline Female & 542 & 55.8 \\
\hline \multicolumn{3}{|l|}{ Marital status } \\
\hline Married or living with partner & 602 & 62.1 \\
\hline Single & 67 & 6.9 \\
\hline Divorced & 107 & 10.9 \\
\hline Widowed & 194 & 20.1 \\
\hline \multicolumn{3}{|l|}{ Age group } \\
\hline $60-69$ years old & 585 & 60.4 \\
\hline $70-79$ years old & 305 & 31.5 \\
\hline 80 years old or more & 80 & 8.1 \\
\hline \multicolumn{3}{|l|}{ Monthly income $\mathrm{a}^{\mathrm{a}}$} \\
\hline $1-2 \mathrm{MW}$ & 419 & 53.3 \\
\hline $2.1-3 \mathrm{MW}$ & 247 & 31.4 \\
\hline$>3 \mathrm{MW}$ & 120 & 15.3 \\
\hline \multicolumn{3}{|l|}{ Education $^{\mathrm{a}}$} \\
\hline Did not go to school & 61 & 6.3 \\
\hline Incomplete elementary school & 317 & 32.8 \\
\hline Complete elementary school & 239 & 24.8 \\
\hline Complete high school & 192 & 19.9 \\
\hline Complete college & 156 & 16.2 \\
\hline \multicolumn{3}{|l|}{ Race $^{\mathrm{a}}$} \\
\hline White & 732 & 75.9 \\
\hline Black & 124 & 12.9 \\
\hline Asian/Native indian & 108 & 11.2 \\
\hline \multicolumn{3}{|l|}{ Retirement $^{\mathrm{a}}$} \\
\hline Yes & 701 & 72.9 \\
\hline No & 260 & 27.1 \\
\hline \multicolumn{3}{|l|}{ Perception of health } \\
\hline Excellent & 245 & 25.3 \\
\hline Very good/good & 513 & 52.9 \\
\hline Bad/regular & 212 & 21.8 \\
\hline \multicolumn{3}{|l|}{ Use of medications $\mathrm{s}^{\mathrm{a}}$} \\
\hline None & 259 & 26.8 \\
\hline $1-2$ & 518 & 53.6 \\
\hline More than 2 & 190 & 19.6 \\
\hline
\end{tabular}

aVariables with missing cases; $\mathrm{MW}=$ reference minimum wage from the demographic Census 2017 form the Brazilian Institute of Geography and Statistics (IBGE) - R\$ 937,00.

The health profile of older adults (Table 1) showed that most participants perceived their health as very good/good (52.9\%) and took up to 2 medications regularly (53.6\%). The assessment of perceived barriers for physical activity showed extended study hours, concern 
with physical appearance, lack of equipment, and lack of social support from family/friends are the main reasons that prevent older adults from engaging in physical activity (Table 2).

Table 2 - Identification of perceived barriers for physical activity among older adults in the city of Maringá, Paraná, Brazil ( $n=960)$.

\begin{tabular}{lrrrr}
\hline \multirow{2}{*}{\multicolumn{1}{c}{ Barriers for physical activity }} & \multicolumn{2}{c}{$\begin{array}{c}\text { Non-perceived } \\
\text { barrier }\end{array}$} & \multicolumn{2}{c}{$\begin{array}{c}\text { Perceived } \\
\text { barrier }\end{array}$} \\
\cline { 2 - 5 } & \multicolumn{1}{c}{$\mathrm{n}$} & \multicolumn{1}{c}{$\%$} & $\mathrm{n}$ & $\%$ \\
\hline Extensive work hours & 143 & 14.7 & 827 & 85.3 \\
Extensive study hours & 31 & 3.2 & 939 & 96.8 \\
Family commitments & 294 & 30.3 & 676 & 69.7 \\
Lack of adequate weather & 514 & 53.0 & 456 & 47.0 \\
Lack of available space & 106 & 10.9 & 864 & 89.1 \\
Lack of equipment & 95 & 9.8 & 875 & 90.2 \\
Household chores & 287 & 29.6 & 683 & 70.4 \\
Lack of company & 209 & 21.5 & 761 & 78.5 \\
Lack of social support & 99 & 10.2 & 871 & 89.8 \\
Lack of financial resources & 107 & 11.0 & 863 & 89.0 \\
Moodiness & 140 & 14.4 & 830 & 85.6 \\
Fear of injuries & 258 & 26.6 & 712 & 73.4 \\
Physical limitations & 215 & 22.2 & 755 & 77.8 \\
Mild pain or discomfort & 314 & 32.4 & 656 & 67.6 \\
Lack of energy & 249 & 25.7 & 721 & 74.3 \\
Lack of physical abilities & 174 & 17.9 & 796 & 82.1 \\
Lack of knowledge on physical activity & 226 & 23.3 & 744 & 76.7 \\
Unsafe environment & 143 & 14.7 & 827 & 85.3 \\
Concern with physical appearance & 57 & 5.9 & 913 & 94.1 \\
Lack of interest & 109 & 11.2 & 861 & 88.8 \\
\hline
\end{tabular}

When stratifying according to gender (Table 3), reasons such as "household chores", "lack of companionship", "fear of getting injured", "physical limitations", "insufficiently safe environment", and "concern about physical appearance" were significantly $(p<0.05)$ more frequently among males.

When barriers were stratified by age group of older adults, an increase tendency was observed in the extended work hours $(\mathrm{p}=0.022)$ with the increase of age ( $\mathrm{Ta}-$ ble 4). On the other hand, there was a decrease tendency of perceived physical limitations $(p=0.010)$ as a barrier for physical activity with the increase of age (Table 4).

When barriers were stratified by perception of health of participants (Table 5), an increase tendency was found for perception of lack of equipment $(\mathrm{p}=$ $0.047)$, fear of getting injured ( $p=0.001)$, physical limitations $(p=0.001)$, mild pain or discomfort $(p=0.001)$ and lack of interest $(\mathrm{p}=0.03)$ according improved perception of health (excellent and very good/good).

\section{Discussion}

The present study sought to verify which barriers for physical activity were perceived by older adults users of fitness zones in the city of Maringá - Paraná. It was found that participants in general presented a high perception of barriers for physical activity in FZ. Opposite to what was expected, there was increased tendency of perception of barriers for older adults according to their improved self-assessed health. According to gender, males showed more barriers for physical activity than females. Moreover, the older in age, the more extended work hours become a more frequent barrier, while physical limitations decrease with older age.

There was a great number of barriers for physical activity in FZ by older adults. This indicates that this population has many restrictions when using the public environment as a tool in the search for an active life.

Older adults are a part of the population that deserves direct attention when it comes to physical activity ${ }^{9,16}$, since they are very susceptible to any sort of adversity. This can be a reason why older adults see physical activity with a certain apprehension, sub estimating their own potential and facing diverse environmental and personal barriers for an active life.

Physical activity when done properly can promote health for older adults and make them prone to continue to be active ${ }^{3}$. This indicated the need for supervised activities for this population to guarantee the safety of the elderly. That is a factor that has been already pointed out as a concern in FZ, being a place where there is a lack of professionals to correctly guide the activities ${ }^{9}$. $\mathrm{FZ}$ are locations with equipment that aim to improve the many physical capacities ${ }^{9}$. Nonetheless, those same equipment can be factors that do not promote the continuity of physical activity. Because it requires guidance for its correct use, the lack of professionals in those locations bring discontent by users for not being sure on how to use them ${ }^{9}$ and how to correctly perform an exercise session.

Even with many barriers for physical activity, some differences were noticed in the present study. Contrary to the hypothesis of this study, older adults with better self-perception of health showed more barriers for physical activity than those with regular/bad perception of health (Table 5). This could be an indicator that older adults with lower perception of health understand the need for an active lifestyle, and could have more interest in improving health and motivating themselves for physical activity. 
Table 3 - Perceived barriers for physical activity among older adults in the city of Maringá, Paraná, Brazil, stratified by gender ( $\mathrm{n}=960$ ).

\begin{tabular}{|c|c|c|c|c|c|c|}
\hline \multirow{3}{*}{ Barriers for Physical Activity } & \multicolumn{4}{|c|}{ Gender } & \multirow{3}{*}{$\mathrm{X}^{2}$} & \multirow{3}{*}{$\mathrm{P}$} \\
\hline & \multicolumn{2}{|c|}{ Male } & \multicolumn{2}{|c|}{ Female } & & \\
\hline & $\mathrm{n}$ & $\%$ & $\mathrm{n}$ & $\%$ & & \\
\hline Extensive work hours & 368 & 85.8 & 459 & 84.8 & 0.167 & 0.682 \\
\hline Extensive study hours & 414 & 96.5 & 525 & 97.0 & 0.225 & 0.635 \\
\hline Family commitments & 305 & 71.1 & 371 & 68.6 & 0.719 & 0.397 \\
\hline Lack of adequate weather & 198 & 46.2 & 258 & 47.7 & 0.226 & 0.634 \\
\hline Lack of available space & 382 & 89.0 & 482 & 89.1 & 0.001 & 0.980 \\
\hline Lack of equipment & 394 & 91.8 & 481 & 88.9 & 2.328 & 0.127 \\
\hline Household chores & 339 & 79.0 & 344 & 63.6 & 27.361 & $0.001^{*}$ \\
\hline Lack of company & 351 & 81.8 & 410 & 75.8 & 5.151 & $0.023^{*}$ \\
\hline Lack of social support & 386 & 90.0 & 485 & 89.6 & 0.028 & 0.867 \\
\hline Lack of financial resources & 385 & 89.7 & 478 & 88.4 & 0.470 & 0.493 \\
\hline Moodiness & 366 & 85.3 & 464 & 85.8 & 0.040 & 0.842 \\
\hline Fear of injuries & 331 & 77.2 & 381 & 70.4 & 5.553 & $0.018^{*}$ \\
\hline Physical limitations & 350 & 81.6 & 405 & 74.9 & 6.270 & $0.012^{*}$ \\
\hline Mild pain or discomfort & 290 & 67.6 & 366 & 67.7 & 0.001 & 0.986 \\
\hline Lack of energy & 327 & 76.2 & 394 & 72.8 & 1.446 & 0.229 \\
\hline Lack of physical abilities & 357 & 83.2 & 439 & 81.1 & 0.697 & 0.404 \\
\hline Lack of knowledge on physical activity & 333 & 77.6 & 411 & 76.0 & 0.365 & 0.546 \\
\hline Unsafe environment & 379 & 88.3 & 448 & 82.8 & 5.883 & $0.016^{*}$ \\
\hline Concern with physical appearance & 411 & 95.8 & 502 & 92.8 & 3.927 & $0.048^{*}$ \\
\hline Lack of interest & 383 & 89.3 & 478 & 88.4 & 0.204 & 0.651 \\
\hline
\end{tabular}

* Significant difference $=\mathrm{p}<0.05$ (Chi-squared test).

Table 4 - Perceived barriers for physical activity among older adults in the city of Maringá, Paraná, Brazil, stratified by age group ( $\mathrm{n}=960$ ).

\begin{tabular}{|c|c|c|c|c|c|c|c|c|}
\hline \multirow{3}{*}{ Barriers for Physical Activity } & \multicolumn{6}{|c|}{ Age group } & \multirow{3}{*}{$\mathrm{X}^{2}$} & \multirow{3}{*}{$\mathrm{P}$} \\
\hline & \multicolumn{2}{|c|}{$60-69$} & \multicolumn{2}{|c|}{$70-79$} & \multicolumn{2}{|c|}{$80+$} & & \\
\hline & $\mathrm{n}$ & $\%$ & $\mathrm{n}$ & $\%$ & $\mathrm{n}$ & $\%$ & & \\
\hline Extensive work hours & 489 & 83.4 & 265 & 86.9 & 73 & 92.4 & 5.251 & $0.022^{*}$ \\
\hline Extensive study hours & 568 & 96.9 & 296 & 97.0 & 75 & 94.9 & 0.392 & 0.531 \\
\hline Family commitments & 419 & 71.5 & 195 & 63.9 & 62 & 78.5 & 0.159 & 0.690 \\
\hline Lack of adequate weather & 272 & 46.4 & 141 & 46.2 & 43 & 54.4 & 0.875 & 0.350 \\
\hline Lack of available space & 522 & 89.1 & 270 & 88.5 & 72 & 91.1 & 0.065 & 0.798 \\
\hline Lack of equipment & 536 & 91.5 & 271 & 88.9 & 68 & 86.1 & 3.209 & 0.073 \\
\hline Household chores & 406 & 69.3 & 213 & 69.8 & 64 & 81.0 & 2.694 & 0.101 \\
\hline Lack of company & 458 & 78.2 & 239 & 78.4 & 64 & 81.0 & 0.209 & 0.648 \\
\hline Lack of social support & 531 & 90.6 & 267 & 87.5 & 73 & 92.4 & 0.205 & 0.650 \\
\hline Lack of financial resources & 528 & 90.1 & 264 & 86.6 & 71 & 89.9 & 0.894 & 0.344 \\
\hline Moodiness & 496 & 84.6 & 265 & 86.9 & 69 & 87.3 & 0.942 & 0.332 \\
\hline Fear of injuries & 439 & 74.9 & 220 & 72.1 & 53 & 67.1 & 2.454 & 0.117 \\
\hline Physical limitations & 468 & 79.9 & 235 & 77.0 & 52 & 65.8 & 6.615 & $0.010^{*}$ \\
\hline Mild pain or discomfort & 414 & 70.6 & 184 & 60.3 & 58 & 73.4 & 1.964 & 0.161 \\
\hline Lack of energy & 437 & 74.6 & 225 & 73.8 & 59 & 74.7 & 0.017 & 0.896 \\
\hline Lack of physical abilities & 485 & 82.8 & 244 & 80.0 & 67 & 84.8 & 0.064 & 0.800 \\
\hline Lack of knowledge on physical activity & 463 & 79.0 & 223 & 73.1 & 58 & 73.4 & 3.634 & 0.057 \\
\hline Unsafe environment & 500 & 85.3 & 265 & 86.9 & 62 & 78.5 & 0.655 & 0.418 \\
\hline Concern with physical appearance & 557 & 95.1 & 284 & 93.1 & 72 & 91.1 & 2.742 & 0.098 \\
\hline Lack of interest & 526 & 89.8 & 264 & 86.6 & 71 & 89.9 & 0.619 & 0.431 \\
\hline
\end{tabular}

*Significant difference $=\mathrm{p}<0.05$ (Chi-squared test). 
Table 5 - Perceived barriers for physical activity among older adults in the city of Maringá, Paraná, Brazil, stratified by perception of health $(\mathrm{n}=960)$.

\begin{tabular}{|c|c|c|c|c|c|c|c|c|}
\hline \multirow{3}{*}{ Barriers for Physical Activity } & \multicolumn{6}{|c|}{ Perception of Health } & \multirow{3}{*}{$\mathrm{X}^{2}$} & \multirow{3}{*}{$\mathrm{P}$} \\
\hline & \multicolumn{2}{|c|}{ Excellent } & \multicolumn{2}{|c|}{ Very good/good } & \multicolumn{2}{|c|}{ Regular/bad } & & \\
\hline & $\mathrm{n}$ & $\%$ & $\mathrm{n}$ & $\%$ & $\mathrm{n}$ & $\%$ & & \\
\hline Extensive work hours & 213 & 86.9 & 440 & 85.8 & 174 & 82.1 & 2.058 & 0.151 \\
\hline Extensive study hours & 239 & 97.6 & 497 & 96.9 & 203 & 95.8 & 1.164 & 0.281 \\
\hline Family commitments & 180 & 73.5 & 348 & 67.8 & 148 & 69.8 & 0.841 & 0.359 \\
\hline Lack of adequate weather & 117 & 47.8 & 231 & 45.0 & 108 & 50.9 & 0.373 & 0.541 \\
\hline Lack of available space & 212 & 86.5 & 472 & 92.0 & 180 & 84.9 & 0.153 & 0.696 \\
\hline Lack of equipment & 222 & 90.6 & 473 & 92.2 & 180 & 84.9 & 3.811 & $0.047^{*}$ \\
\hline Household chores & 180 & 73.5 & 357 & 69.6 & 146 & 68.9 & 1.219 & 0.270 \\
\hline Lack of company & 201 & 82.0 & 398 & 77.6 & 162 & 76.4 & 2.228 & 0.136 \\
\hline Lack of social support & 224 & 91.4 & 460 & 89.7 & 187 & 88.2 & 1.298 & 0.255 \\
\hline Lack of financial resources & 221 & 90.2 & 454 & 88.5 & 188 & 88.7 & 0.296 & 0.586 \\
\hline Moodiness & 210 & 85.7 & 444 & 86.5 & 176 & 83.0 & 0.589 & 0.443 \\
\hline Fear of injuries & 194 & 79.2 & 389 & 75.8 & 129 & 60.8 & 18.663 & $0.001^{*}$ \\
\hline Physical limitations & 202 & 82.4 & 412 & 80.3 & 141 & 66.5 & 15.840 & $0.001^{*}$ \\
\hline Mild pain or discomfort & 189 & 77.1 & 339 & 66.1 & 128 & 60.4 & 14.978 & $0.001^{*}$ \\
\hline Lack of energy & 186 & 75.9 & 378 & 73.7 & 157 & 74.1 & 0.230 & 0.632 \\
\hline Lack of physical abilities & 213 & 86.9 & 409 & 79.7 & 174 & 82.1 & 2.115 & 0.146 \\
\hline Lack of knowledge on physical activity & 190 & 77.6 & 391 & 76.2 & 163 & 76.9 & 0.035 & 0.852 \\
\hline Unsafe environment & 212 & 86.5 & 441 & 86.0 & 174 & 82.1 & 1.697 & 0.193 \\
\hline Concern with physical appearance & 235 & 95.9 & 479 & 93.4 & 199 & 93.9 & 0.967 & 0.326 \\
\hline Lack of interest & 231 & 94.3 & 448 & 87.3 & 182 & 85.8 & 8.533 & $0.003^{*}$ \\
\hline
\end{tabular}

*Significant difference $=\mathrm{p}<0.05$ (Chi-squared test) .

People who engage in physical activity knowing its importance for themselves tend to be more motivated to be active ${ }^{17}$. A study showed that continuous physical activity can be a fator that promotes greater perception of facilitators than barriers for older adults ${ }^{10}$. Therefore, these older adults who perceived their health as regular/bad must continue to engage in physical activities in order to take advantage of their will to improve.

On the other hand, older adults with very good/ good and excellent perceptions of health related their barriers specially in the environment of $\mathrm{FZ}$ and what such locations could offer for physical activity (Table 5).

Since physical activity results in constant adaptation, these results could have been due to characteristics of the FZ. These locations, which promote the start and maintenance of users for physical activity, does not provide the necessary resources for the progressive development of physical exercise, leading to physical adaptation and/or unwanted results from the lack of professional guidance ${ }^{9}$. Therefore, for these older adults who already perceive a better health condition, the recommendation is to search for other specialized environments for promotion and guidance in physical exercise such as gyms, specially those focused on the elderly.

Another result found was that older men presented greater barriers for physical activity in FZ (Table 3). Multiple studies have shown females are the ones usually more concerned about caring for health ${ }^{18,19}$. Being less engaged in responsibilities related to health, males tend to find greater barriers to maintaining a healthy lifestyle, as found in the present study. Nonetheless, other authors ${ }^{18}$ pointed that physical activity is one of the main and few means through which males found a way to maintain good health, contrary to what was found on this study, which showed barriers for physical activity in FZ. On the other hand, two previous studies identified that there were more older adult females in $\mathrm{FZ}^{9,20}$. This is na indication that FZ may be locations that do not attract males for physical activity, being this a possible strategy that need to be implemented to attract such population for an active lifestyle.

On age and its relationship to perceived barriers, younger older adults perceived more barriers related to physical limitations than those of more advanced age who saw extensive work hours as the greatest barrier for physical activity in FZ. Initiating physical activities may 
demand too much effort, coming from different sources.

Main motives are linked to the improvement of disease and health, and living ageing in a healthy manner ${ }^{21}$. From this perspective, many older adults initiate physical activities when first reaching their elderly age by medical prescription resulting from their health status and physical limitations, and end up remaining in those practices due to the benefits these activities offer on their daily lives and the functionality of daily activities ${ }^{16,21}$. From then on, people continue to engage and are more motivated and have less reasons to interrupt the activities ${ }^{17}$. However, older adults with a continuous work load as they age could make it worse from 80 years old on.

Though relevant results were verified in this study, important limitations must be mentioned. Initially, the sample selection methods were intentional and by convenience. Though this method could lead to research bias, several criteria were used to avoid it such as the stratification of the city in different regions e selection of $\mathrm{FZ}$ within each of the regions randomly, a large sample size to better represent the population using $\mathrm{FZ}$ in the metnioned city. It is still necesasry to emphasize that the sample only included users of $\mathrm{FZ}$ in one city. Even though that is a characteristic of the sample, it is relevant by the large number of $\mathrm{FZ}$ present in the same city, and by the size of the city (approximately 400 thousand inhabitants), which presents a large variety of sociodemographic characteristics, resulting in a broader amount of attributes for the outcomes of the study.

In conclusion, older adults users of $\mathrm{FZ}$ perceived a great barrier for physical activity. Furthermore, older adults with a certain profile tend to recognize more barriers for the use of FZ, and justify it mainly by physical limitations and the fear of getting injured during the activities. In face of this, major attention must be put by city governments and health professionals that deal with this population, since there are many $\mathrm{FZ}$ in the city and there is little supervision of users in these public spaces. Therefore, there should be a better interaction between city hall and social programs that promote physical activity for the population, so there are fewer barriers and restrictions when searching for a healthy lifestyle in public places in the cities, as well as better guidance for healthy older adults that already use FZ in order to show them other specialized locations for the prescription of physical exercise.

\section{Conflicts of interest}

The authors declare there no conflicts of interest.

\section{Authors' contributions}

Oliveira DA, contributed in the conceptualization of the study, data analysis, writing, and review of the manuscript. Moreira CA, contributed in the data analysis, writing, and critical review of the manuscript. Nascimento Júnior JRA, contributed in the initial conceptualization of the study, data analysis, and critical review of the manuscript. Rodrigues GLD, contributed in data collection. Silva DA, contributed in data collection. Cavaglieri CR, contributed in the critical review of the manuscript.

\section{References}

1. Ervatti L, Borges GM, Ponte Jardim A. Demographic change in Brazil in the beginning for the 21st century: subsidy for population projections. IBGE, Instituto Brasileiro de Geografia e Estatística, 2015.

2. Wong LLR, Carvalho JA. The rapid process of population ageing in Brazil: serious challenged for public policies. Rev Bras Estud Popul. 2006;23(1):5-26.

3. Krug RDR, Mazo GZ, Lopes MA. Barriers and facilitators for physical activity in older adult females who are physically inactive. Rev Bras Med Esporte. 2015;21(1):57-64.

4. Maciel MG, Saraiva LAS, Carvalho MN. Assessment of social programs for physical activity: conceptual notes on the effectivity as a paramenter for development. LICERE. 2017;20(2):455-82.

5. Amorim T, Knuth A, Cruz D, Malta D, Reis R, Hallal P. Description of municipal programs for physical activity promotion funded by the Ministry of Health. Rev Bras Ativ Fís Saúde. 2013;18(1):63-74.

6. Müller WA, Silva MC. Barriers for physical activity in adolescentes in a rural area in Rio Grande do Sul. Rev Bras Ativ Fís Saúde. 2013;18(3):344-53.

7. Pinto A, Claumann G, Cordeiro P, Felden E, Pelegrini A. Perceived barriers for physical activity among college students in Physical Education. Rev Bras Ativ Fís Saúde. 2017;22(1):66-75.

8. Esteves JVDC, Andreato LV, Moraes SMF, Prati ARC. Lifestyle of users physically active in Fitness Zones in Maringá-PR. Conexões. 2010;8(1):119-29.

9. Costa B, Freitas C, Silva K. Physical activity and use of equipment among users of Fitness Zones. Rev Bras Ativ Fís Saúde. 2016;21(1):29-38.

10. Sandreschi PF, Menezes EC, Krug RDR, Lopes MA, Mazo GZ. Perception of physically inactive and active older adult females on barriers and facilitators for physical activity. Rev Baiana Saúde Púb. 2014;37(4):914-28.

11. Oliveira JGD, França SPD. Perceived barriers for regular physical activity in older adults. Geriatr Gerontol Aging. 2014;8(3):165-70.

12. Lopes MA, Rosso Krug R, Bonetti A, Mazo GZ. Barriers that influence the non-adoption of long-term physical activity. Rev Bras Ciênc Esporte. 2016;38(1):76-83.

13. Folstein MF, Folstein SE, McHugh PR. Mini-Mental State: a practical method for grading the cognitive state of patients for clinician. J Psychiatr Res. 1975;12:189-98.

14. Brucki SM, Nitrini R, Caramelli $\mathrm{P}$, Bertolucci PHF, Okamoto IH. Suggestions for the use of the mini-health status examination in Brazil. Arq Neuropsiquiatr. 2003;61(3):777-81.

15. Martins MDO, Petroski EL. Measuring perceived barriers for physical activity: a proposed instrument. Rev Bras Cineantropom Desempenho Hum. 2000;2(1):58-65. 
16. Carvalho DA, Brito AF, Dos Santos MAP, Nogueira FRS, Moura Sá GG, Oliveira Neto JG, et al. Prevalence of physical exercise in older adults and its relationship with difficulties and lack of specific professional counseling. Rev Bras $\mathrm{Ci}$ e Mov. 2017;25(1):29-40.

17. Deci EL, Ryan RM. Self- determination theory. Am Psychologist. 2000;5(1):66-78.

18. Costa SP, Menandro MCS. Social representations of health and care for older adult males and females. Saude Soc. 2014;23(2):626-40.

19. Costa-Júnior FMD, Couto MT, Maia ACB. Gender and care in health: concepts from professionals working in ambulatory and hospital contexts. Sex Salud Soc. 2016;(23):97-117.
20. Pinheiro WL, Coelho Filho M. Profile of older adult users of fitness zones. Rev Bras Promoç Saúde. 2017;30(1):93-101.

21. Cavalli AS, Vargas Pogorzelski L, Domingues MR, Rosa Afonso M, Ribeiro JAB, Cavalli MO. Motivation for physical activity in older adults: comparative study between two university programs - Brazil and Portugal. Rev Bras Geriatr Gerontol. 2014;17(2):255-64.

Received: 26/09/2017

Approved: 01/09/2018

Quote this article as:

Oliveira DV, Moreira CR, Nascimento Junior JRA, Rodrigues GLD, Silva DA, Cavaglieri CR. Barriers for physical activity of older adults users of fitness zones. Rev Bras Ativ Fis Saúde. 2018;23:e0025. DOI: 10.12820/rbafs.23e0025 